\title{
Teaching for Understanding in Engineering Education
}

\author{
http://dx.doi.org/10.3991/ijep.v3iS1.2402 \\ H. Kipper and T. Rüütmann \\ Tallinn University of Technology, Tallinn, Estonia
}

\begin{abstract}
The article introduces effective teaching strategies and models suitable for teaching engineering, implemented at Estonian Centre for Engineering Pedagogy. Introduced models are designed to capitalize deep understanding and critical thinking in teaching engineering. Accordingly students will be able to explain, find evidence and examples, generalise, apply, analogise and represent a topic in a new way. At least four different kinds of knowledge are essential for expert teaching: knowledge of content; pedagogical content knowledge; general pedagogical knowledge; and knowledge of learners and learning. The goal of the article is to help engineering teachers acquire knowledge in each of these areas.
\end{abstract}

Index Terms - Critical thinking, deep understanding, engineering education, teaching models, teaching strategies.

\section{INTRODUCTION}

The field of engineering education continues to evolve rapidly. Cognitive views of learners are now the primary guide for teaching engineering, being reflected in greater emphasis on psychological aspects and social interaction as essential factors in learning, the importance of learners' prior knowledge, the influence of context on learning, and the general acceptance that learners construct their understanding of the topics they study. Additionally the interdependence of learning and motivation is more fully understood in order to acquire a deep understanding of the studied topics while simultaneously developing students' critical thinking abilities.

According to Entwistle [1] students may be inclined to approach their courses in one of three ways. Those with a reproducing orientation tend to take a surface approach to learning, relying on rote memorization and mechanical formula substitution and making little or no effort to understand the material being taught. Those with a meaning orientation tend to adopt a deep approach, probing and questioning and exploring the limits of applicability of new material. Those with an achieving orientation tend to use a strategic approach, doing whatever is necessary to get the highest grade they can, taking a surface approach if that suffices and a deep approach only when necessary.

In order to have clearer understanding of the thinking systems, it is necessary to look at the modalities that affect the way teachers teach and the way students learn. According to Tileston [2] about $99 \%$ of all we learn comes to us through the senses. The brain takes about 15 seconds to decide what to pay attention and what to discard. Approximately $98 \%$ of the information coming through the senses is discarded. That means that $98 \%$ of the informa- tion going to your students in the form of words, pictures, smells, tastes and touch is lost. No wonder they don't even remember!

Expert teachers generally are comfortable with wide range of teaching strategies, varying them skilfully according to the learning task and learners' needs. Some of these are general strategies, such as skilled questioning, clear communication, organizing lessons, and effective feedback, starting lessons with a review and ending with closure, applicable in all teaching situations. Other, more explicit strategies, called teaching models, are grounded in learning and motivation theory and designed to reach specific learning objectives. All of them are designed to help students develop a deep understanding of the topics they study and improve their critical-thinking abilities.

According to Eggen \& Kauchak [3] research indicates that at least four different forms of knowledge are essential for expert teaching for understanding:

- Knowledge of content - we can't teach what we don't understand, a thorough understanding of the topics we teach is essential for all teachers in all content areas;

- Pedagogical content knowledge - the ability to create examples, the understanding of ways of representing the subject that make it comprehensible to others and an understanding of what makes the learning of specific topics easy or difficult. The difference between content knowledge and pedagogical content knowledge is similar to the difference between knowing that and knowing how;

- General pedagogical knowledge - involves an understanding of general principles of instruction and classroom management that transcends individual topics or subject matter areas. Questioning is an important example, it is a teaching strategy that applies to every area teaching. Similarly teachers must be able to communicate clearly, provide effective feedback, and use other strategies;

- Knowledge of learners and learning - is essential to effective teaching, being arguably the most important knowledge a teacher can have. It influences the way we teach by reminding us that we do not teach content, we teach students. Teachers' ability to adapt their instruction based on what learners' know is essential for effective teaching.

Each of the forms of knowledge, introduced above is essential for teaching expertise in teaching for understanding. The goal of the article is to help engineering teachers acquire knowledge in each of these areas. The teaching models and strategies described in this article are being 
taught at Estonian Centre for Engineering Pedagogy (ECEP) at Tallinn University of Technology (TUT) to help engineering teachers ensure that their students' learning extends beyond mere memorisation, which is too prevalent at schools today.

\section{TEACHING FOR UNDERSTANDING}

\section{A. Strategies and Models}

Accordingly to Eggen \& Kauchak [3] strategies are general approaches to instruction that apply in a variety of content areas and are used to meet a range of learning objectives. For example questioning, organising lessons, providing feedback, starting lessons with a review and ending with closure, applicable in all teaching situations. These strategies are general and apply across instructional settings, regardless of the grade, level, content area or topic.

Models are specific approaches to instruction that have four characteristics [3]:

- They are designed to help students acquire deep understanding of specific forms of content and to develop their critical-thinking abilities;

- They include a series of specific steps that are intended to help students reach the objectives;

- They are grounded in learning theory;

- They are supported by motivation theory.

General strategies are incorporated within each of the models. For example questioning, lesson organisation, feedback and other strategies are essential for the success of all models. A model provides structure and direction for the teacher, but it cannot provide all actions taken by a teacher. A teaching model is not a substitute for basic teaching skills, it cannot take the place of qualities a good teacher must have, and the different forms of knowledge. A teaching model is a tool, designed to help teachers make their instruction systematic and efficient [3].

\section{B. Teaching for Thinking and Understanding}

The concept of teaching for understanding may seem ironic as no teacher teaches for lack of understanding. Experts define understanding as being able to do variety of thought-demanding procedures with a topic - like explaining, finding evidence and examples, generalising, applying, analogising, and representing the topic in a new way [3].

Teaching for understanding requires that teachers possess the different types of knowledge introduced earlier. According to Eggen \& Kauchak [3] and Burden \& Byrd [4] armed with this knowledge, effective teachers achieve deep student understanding by:

- Identifying clear learning objectives for students;

- Selecting teaching strategies that most effectively help students reach the objectives;

- Providing examples and representations that help students acquire a deep understanding of the topics they study;

- Guiding students as they construct their understanding of the topic being studied;

- Continually monitoring students for evidence of learning.
Although the focus is on learning and learners, strategies introduced above demonstrate the essential role that teachers as well as teacher knowledge play in guiding this process. Effective teaching strategies are essential for teachers to promote deep understanding. It is important to be able to select and use strategies that are most effective for different learning objectives.

A term of generative knowledge, knowledge that can be used to interpret new situations, to solve problems, to think and reason, and learn, is often used to describe deep understanding. Generative knowledge involves learning both, content and the ability to think critically. If deep understanding of content is a goal, emphasis on thinking must also be a goal. In order to think effectively and productively in an area, a student must possess great deal of generative knowledge about the area.

Critical thinking is the ability and disposition to make and assess conclusions based on evidence. Critical thinking includes following abilities:

- Confirming conclusions with facts;

- Identifying un-stated assumptions;

- Recognising overgeneralisations and undergeneralisations;

- Identifying relevant and irrelevant information;

- Identifying bias, stereotypes, clichés and propaganda.

Students learn these attitudes through teacher modelling and by directly experiencing them in classroom activities. As students acquire these inclinations and develop critical thinking skills, their abilities to both learn and function effectively in the real world increases. Fortunately, teaching for thinking also increases learner motivation.

Lang \& Evans [5], and Raths et al [6] describe a widely used classification system, focusing attention on teaching following thinking operations, suitable for engineering education:

- Comparing - look for similarities and differences by observing details, find and sort similarities, search and sort differences, and summarise in a list;

- Observing - observing should lead to more accurate data on which to base conclusions, and to greater understanding;

- Classifying - examining and assortment of items and sorting them into related groups. Each group is given a name, students can process data mentally and organise them systematically. Classifying requires three steps: examining data, creating categories, and placing items in categories;

- Hypothesising - students are to come up with a variety of possible explanations for a question, problem, situation, thus identifying alternative possibilities and deciding which have the most credibility;

- Criticising - ask students to evaluate, make judgements and offer opinions to sharpen their sense of what is desirable or undesirable, high or low quality, significant or trivial;

- Looking for assumptions - taking something for granted or assume - being probably true or probably false thus students can learn to identify assumptions. Learning to differentiate between what is assumed to be true and what is observable fact is at the heart of logical reasoning; 
- Collecting and organising data - requires several skills: locating information, examining the data and selecting relevant to the inquiry, developing procedures that allow data to be assembled, organising data;

- Summarising - requires condensing and distilling the core message from a piece of work. Students must state the main ideas, differentiating between what is important and what may be left out, thus increasing students' abilities to understand;

- Coding - communicate ideas in "shorthand", as a thinking operation, coding is a system for pointing out through patterns or expressions;

- Interpreting - explaining the meaning, skilful interpretation increases meaning and understanding.

Facts and information are the important raw materials for thinking. Knowing how and having the skills to access and use these to think is at least as important.

A second approach to teaching basic thinking operations and core thinking skills suitable for engineering education is outlined by Hughes \& Jones [7]:

- Focusing - define the problem and set goals (shortand long-term outcomes);

- Information gathering - observe and ask questions, pick relevant information and clarify issues;

- Remembering - encode (repeat information, use associations) and recall (bring to consciousness, when, where or how information was learned);

- Organising - compare, identify similarities and differences, classify (group, categorise or sequence items), order and represent showing relations;

- Analyse - attributes and components are identifies, relationships and patterns are determined, main ideas and errors are identified;

- Generating - generate new ideas by inferring (identifying what reasonably may be true), predicting (anticipating what will likely happen) and elaborating (adding details, explanations, examples);

- Integrating - integrate what we have learned, summarise (condense, select, combine) and restructure (combine new knowledge with old into something new)

- Evaluate - criteria are established and the solution is verified.

Carolyn Hughes [7] confirms that content can be of increasing difficulty and that teachers should recognise that teaching/learning experiences (concrete, graphic, abstract) should match learner readiness.

\section{Strategies Promoting Student Understanding}

According to Burden \& Byrd [4], Eggen \& Kauchak [3], Marzano et al [8], and Melezinek [9] research on teaching provides guidance for the use of specific strategies to enhance student understanding. These essential teaching strategies are the teacher attitudes and skills necessary to ensure that all students learn and understand as much as possible, being the basic skills of teaching. Following specific teaching strategies that were proven to have a high probability of enhancing student achievement:

- Set objectives and provide feedback - give students direction and help them think about their own learn- ing. Both short-term goals and long-term goals need to be clearly visible to students in language they can understand;

- Instructional alignment - congruence among objectives, learning activities and assessments, being essential if teachers help students learn as much as possible;

- Review and closure - review is the process of summarising previous work and forming a link between learning and the present topic; closure is a form of review that occurs at the end of a lesson;

- Teacher characteristics - teachers set emotional tone for the classroom, design, identify and implement learning objectives and activities, create examples, designed to understand the topic, assess student learning. Teacher characteristics such as personal teaching efficacy, modelling and enthusiasm, caring, respect and high expectations promote learner motivation, being linked to increased student achievement;

- Communication - following elements of effective communication influence learning: precise terminology (teacher language that eliminates vague terms from presentations), connected discourse (type of teacher presentations that is clear, thematic, logical and leads to a point), transition signals (verbal statements that communicate that one idea is ending and another is beginning), emphasis (the use of verbal statements, vocal inflection, or repetition to alert students to important information), clear language and knowledge of content, congruent verbal and nonverbal behaviour;

- Organisation - teachers who are organised have students who learn more than their less organised counterparts, time is a key factor: beginning classes promptly, materials prepared in advance, warm-up activities, students perform routine tasks without being told, etc, maximise instructional time;

- Explanation - three main types of explanation may be described: interpretative (what it is), descriptive (how it works), reason-giving (based on generalisations about the world, motives, obligations or values);

- Ask students to identify similarities and differences there are four common approaches to identify similarities and differences: comparing, classifying, creating metaphors, and creating analogies;

- Ask students to summarise content and take notes to distil information, thus involving complex skills: examining information, choosing the most important, restating it in a brief, synthesised mode, deciding, deleting some information, rewording ideas, reorganising information, prioritising;

- Reinforcing efforts to achieve and providing recognition - effort can improve achievement, rewards can be powerful motivators. Use the pause, prompt and praise technique - pause to give students time to identify and correct mistakes, prompt by giving a specific suggestion for improvement, and praise for overcoming the difficulties. Applaud creative solutions, even incorrect ones;

- Homework and practice - give students opportunities to deepen their understanding of and proficiency with 
the content they are learning. Give students the option of cooperating on homework assignments to the greatest possible extent;

- Non-linguistic presentations - use pictures, schematics, graphs, and simple sketches liberally before, during, and after the presentation of verbal material, show films, provide demonstrations and hands-on, if possible;

- Generating and testing hypotheses - involves application of knowledge. Hypothesis generalisation and testing can be approached through inductive and deductive models. Use following tasks: systems analysis (explain the purpose of the system and its parts and functions, describe how the parts affect each other, identify a part of the system, describe a change, test hypothesis), problem solving (solving unstructured problems), invention, experimental inquiry (observations, explanation, prediction, testing), decision making;

- Focus - lesson focus attracts and holds students' attention throughout the learning activity, focus is provided through concrete stimuli (objects, pictures, models, materials displayed, information written on the board, etc) that maintain students' attention during learning activities;

- Feedback - information about current behaviour being used to improve future performance. Effective feedback has three characteristics: it provides specific information, depends on performance, and has a positive emotional tone;

- Monitoring - the process of continually checking students' verbal and nonverbal behaviour for evidence of learning process, being important during all learning activities;

- Motivate learning - as much as possible, relate the material being presented to what has come before and what will to come in the same course, to material in other courses, and particularly to the students' personal experience;

- Provide a balance of concrete information (facts, data, real or hypothetical experiments and their results) and abstract concepts (principles, theories, mathematical models);

- Follow the scientific method in presenting theoretical material - provide concrete examples of the phenomena the theory describes or predicts, then develop the theory or formulate the mod, show how the theory or mod can be validated and deduce its consequences, and present applications;

- Provide intervals - do not fill every minute of class time lecturing and writing on the board. Provide intervals for students to think about what they have been told;

- Provide opportunities to do something active - besides transcribing notes, use interactive lectures (Rüütmann 2009). Small-group activities that take no more than five minutes are extremely effective for this purpose. Provide some open-ended problems, questions and exercises that call for analysis and synthesis.

Questioning is the most effective strategy for promoting understanding - helping students to see connections between abstract ideas and real-world examples, maintaining attention, involving shy and reluctant students, providing emphasis through repetition and assesses students' understanding. It is important to use higher-level questions requiring analysis of the information to promote deeper understanding [10].

The problem is that there is a tendency to ask questions as though rice is thrown at a wedding. Throwing out lots of questions makes the teacher feel good. These questions often do little to support deep understanding but the answers that come back make it feel productive. Carefully focused questions, in the other hand, make all the difference. Focused questions are aimed at a particular target. The target is determined by the stage of the instruction and the nature of understanding to be supported. There must be relevant, accessible prior knowledge or it must be provided or constructed; the relationships must be known or capable of construction; the relevant and irrelevant must be discriminated and a need for inference has to be recognised. The target is likely to be pre-requisite knowledge. Questions, therefore, are aimed at stimulating recall of pre-requisites and practising it. They also serve to indicate where prior knowledge is deficient and needs to be improved. The nature of the question matches the immediate goal of instruction. Teachers often ask mainly factual questions, regardless of the goal.

Merely asking questions does not cause students to think. But higher-level question invite and encourage higher levels of critical thinking in students. Furthermore, it appears that if teachers systematically raise the level of their questioning, students raise level of their responses correspondingly. This requires a carefully planned questioning strategy. Through appropriate questioning student curiosity is fostered. Curiosity is affective dimension of learning and it deals with motivation [10].

Questioning is a primary tool in teaching engineering for leading students into higher order thinking. Students should be asked more how, why, or what do you suppose questions, not only what questions. Knowledge requires memory only, repeating information exactly memorised the what. Comprehension, however, calls for rephrasing, rewording and comparing information. Application requires the learner to apply knowledge and understanding to determine an appropriate, correct answer. Analysis asks students to identify motives or causes, draw conclusions and determine evidence. Synthesis leads students to make predictions, produce original communications, or solve problems. Evaluation causes students to make judgments, offer and support opinions [10].

Through a cleverly planned questioning strategy, a technical teacher can creatively lead students through the cognitive taxonomy of thinking. Carefully devised questions facilitate the observation, communication, comparison, ordering, categorisation, relating, inferring from, and application of information. Beginning with what or the recall questions, in teaching engineering a teacher should lead from the knowledge base into understanding and from understanding into practical application, from application into a more careful analysis, and after analysis into a synthesis or a reassembling of the notion in a new and different way. This entire process can then be assessed and judged as having merit, quality, or worth, teaching students to evaluate all ideas on a consistent set of criteria. 
Technical teachers could promote observation by directing students to "tell us what you see" or to "list the properties that are apparent in the sample" by asking questions like: "What are the dominant characteristics of this subject?”, "What is the object's size and shape?” For comparing information, the scientific thought process that deals with similarities and differences, technical teacher should lead the analytic questioning: "How are these alike?”, "How are these different?”, "Which comes first, second, third?", "On what basis would you group these ideas or objects?”, "What is a different way in which these characteristics can be clustered?”. Following analytic questions, synthesis questions should be asked: "Use the information you have learned to design something new". The final element of reason and thought would be leading students into evaluation by asking for example "Which experimental design was the best? Why?” Related to evaluation is the process of inferring, concluding and deciding. This is the scientific thinking process that deals with ideas remote in time and space: "What can be inferred from this information?", "Predict the outcome and give evidence to support your prediction", "Under what conditions might we extrapolate from this observed information and believe that a similar reaction could occur under a different circumstance?"[10].

Strategies introduced above have been implemented into teaching engineering and are widely in use at Estonian Centre for Engineering Pedagogy (ECEP) at Tallinn University of Technology in teaching engineering educators.

\section{Inductive Model}

The Inductive Model, which is often described as guided discovery, is a straightforward but powerful model designed to help students acquire deep and thorough understanding of well-defined topics. Instead of beginning with general principles and eventually getting applications, the instruction begins with specifics - a set of observations or experimental data to interpret, a case study to analyse, or a complex real-world problem to solve. As the students attempt to analyse the data or scenario or solve a problem, they generate a need for facts, rules, procedures, and guiding principles, at which point they are either presented with the needed information or helped to discover it for themselves.

Grounded in the view that learners construct their own understanding of the world rather than record it in an already-organised form, the model requires teachers to be skilled in questioning and guiding students thinking and making on-the-spot decisions. This is sophisticated and demanding instruction. The model is effective for promoting students involvement and motivation within a safe and supportive learning environment.

Lessons using the Inductive Model begin with and are built around examples. The examples become the experiences that learners use to construct their understanding of the topics they are studying. Social interaction is used to analyse the examples. The teacher guides students towards a more mature understanding and real learning involves personal invention or construction. Clear objectives are as essential when using the Inductive Model as they are with any other instructional format.

According to Prince and Felder [11] the Inductive Model is an umbrella term that encompasses a range of instructional methods, including inquiry learning, problem-based learning, project-based learning, case-based teaching, discovery learning, and just-in-time teaching. These methods have many features in common, besides the fact that they all qualify as inductive. They are all learner-centred they impose more responsibility on students for their own learning than the traditional lecturebased deductive approach does. They are all supported by research findings that students learn by fitting new information into existing cognitive structures. These methods almost always involve students discussing questions and solving problems in class with lot of collaborative or cooperative learning.

The Inductive Model is designed to help students reach two types of learning objectives:

- For students to acquire s deep and thorough understanding of specific and well-defined topics;

- To develop students' critical thinking abilities. Students try to find patterns in the new information and with the teacher's guidance they construct a thorough understanding of the topics and learn to make and assess conclusions based on evidence.

Understanding the differences between principles and generalisations contributes to critical thinking. The validity of conclusions based on generalisations depends on the validity of the generalisations themselves. The abilities to make and assess these conclusions are important criticalthinking skills.

The planning process for lessons using the Inductive Model involves three essential steps:

- Identifying topics - topics may come from textbooks, curriculum guides, or other sources. When the topics are concepts, principles, generalisations, the Inductive Model can be used effectively;

- Specifying learning objectives - clear learning objectives are essential and they provide a framework for planning and implementing lessons;

- Identifying examples - to present all information needed, relationship between concepts, concrete materials, pictures, models, short case studies, simulations.

- Creating examples.

According to Eggen \& Kauchak [3], implementing a lesson using the Inductive Model combines following five interrelated phases, together with an emphasis on thinking and strategies for increasing student motivation:

- Lesson introduction - attract students' attention and provide conceptual framework for the lesson, by using a statement, posing a problem, review of the previous day's work, etc;

- The open-ended phase - promoting student involvement and motivation and ensure their success with an example, emphasise comparing, find patterns and generalise, provide evidence for conclusions;

- Convergent phase - students' responses converge on a specific learning objective, knowledge construction and schema development primarily takes place;

- Closure - occurs when students embed their understanding in a complex schema, encode it into longterm memory, and achieve a sense of equilibrium. This phase provides opportunities to help students 
develop their abilities to recognise irrelevant information, being an important thinking skill;

- Application - typically includes a seatwork or homework assignment, to make the topic meaningful and ensure transfer students must be able to apply it in a real-world context.

Effective assessments are consistent with teacher's objectives. Both paper-and-pencil and performance assessment can be used to measure student understanding. Assessments that capitalise on applications in real-world contexts and include detailed feedback are among the most powerful tools fir increasing learning.

\section{E. The Integrative Model}

The Integrative Model is designed to help students develop a deep understanding of organised bodies of knowledge, topics that combine facts, concepts. Generalisations and the relationships among them are simultaneously developing critical-thinking skills, being related to the Inductive Model. The Integrative Model is grounded in schema theory, that students record information in memory in organised networks of understanding. Concepts are simple forms of understanding that exist in memory (schemas), and when student links concepts to facts, other concepts, principles, generalisations, his/her schemas become much more complex. Teachers using the model attempt to guide students' schemas development as they analyse organised bodies of knowledge.

The Integrative Model is designed to help students reach two independent goals: to construct a deep and thorough understanding of organised bodies of knowledge (topics that combine facts, concepts, generalisations, and relationships among them), and to develop critical thinking abilities. Lessons involve the analysis of data usually presented in a matrix and the data can be gathered by students, teacher or both.

According to Eggen \& Kauchak [3] planning for lessons using the Integrative Model includes the following steps:

- Identifying topics - When topics are organised bodies of knowledge, the Integrative Model can be used effectively; topics may come from textbooks, curriculum guides or other sources;

- Specifying learning objectives - specifying content objectives requires more thought to identify potential generalisations, explanations and possible hypotheses in advance. Students have to find patterns, form explanations, and hypothesise, all on the basis of evidence, thus developing critical thinking skills;

- Preparing data presentation - data is organised in a matrix, data become a background knowledge students use to construct their understanding;

- Capitalising on technology - use databases, computer programmes.

The Integrative Model implementation combines following four closely related phases with emphasis on thinking and strategies for increasing student motivation:

- The Open-ended Phase - beginning point of students' analysis, they observe, describe, compare and search for the patterns in the data;

- The Causal phase - students explain the similarities and differences they identify and look for relation- ships and explainable comparisons, being immersed in critical thinking;

- Hypothetical phase - analyse information, consider possibilities for different conditions;

- Closure and Application - generalise for broad relationships based on the analysis of the data. Summarise the content, promote encoding.

Learners understanding of the topic and their abilities to think critically can be simultaneously measured by having them make and assess conclusions about information from matrices. Assessment should be an integral part of teaching. Assessments should be frequent and thorough with provided detailed feedback.

\section{F. The Model for Direct Instruction}

The Direct-Instruction Model can be used to teach both concepts and procedural skills, being also called explicit instruction. This model uses teacher explanation and modelling combined with student practice and feedback and is teacher-directed.

The Direct-Instruction Model is delivered from several sources, including teacher effectiveness research. It is also based on observational learning theory, which emphasises the importance of modelling for the acquisition of complex behaviours and on the work of Lev Vygotsky, who pointed out the importance of dialogue and social interaction in learning.

Traditionally direct instruction has been associated with "chalk and talk", and, more recently the overhead projector. Today, direct instruction is being increasingly replaced by techniques such as PowerPoint or smart board presentations.

According to Paik [12] effective direct instruction, which is still expected in the modern classroom, should consist of:

- Clear teaching, daily review and homework checks;

- Presentation of new content and skills;

- Teacher monitoring and guided student practice;

- Corrective feedback and instructional reinforcement

- Independent practice at school and at home with 90\% success rate;

- Weekly and monthly evaluations.

Planning with this model begins with the identification of a specific concept or skill. This is followed by identifying prerequisite Planning lessons according to Eggen \& Kauchak [3] using the Direct-Instruction Model involves following four steps:

- Identifying topics - the model is designed to teach concepts and procedural skills;

- Specifying learning objectives - there are two longrange objectives when teaching skills: automaticity (learning a skill to the point that it can be performed with little conscious effort) and transfer (understanding acquired in one setting can be applied in a different setting);

- Identifying prerequisite knowledge - prior knowledge provides "hooks" for new learning, allowing connect new information with what they already understand; 
- Selecting and sequencing problems and examples opportunities to provide practice in learning concepts and skills.

According to Lang \& Evans [5], Eggen \& Kauchak [3], Melezinek [9] implementing a lesson using the DirectInstruction Model occurs in following four phases:

- Introduction and review - attract students' attention and activate their background knowledge through a review of prerequisite knowledge or skills;

- Presentation - explain and illustrate the concept or explain and model the skill being taught, provide examples;

- Guided practice - help students develop perceptions of competence by ensuring success, students try out new content as the teacher carefully monitors their progress and provides support and feedback;

- Independent practice- students practice the new concept or skill on their own first in class, later on a homework assignment.

The key to effective assessment with this model is to ensure that students learn content at a meaningful level. This requires that students work actively with examples and concepts, linking them to the abstraction being taught.

\section{DISCUSSION}

Engineering educators should gain greater confidence through the use of extended range of contemporary teaching tools by obtaining specifics of the art of teaching. Effective strategies and models for teaching thinking skills and capitalizing deep understanding are widely used at ECEP in teaching engineering educators.

A preferable alternative to deductive teaching is inductive teaching and learning, as used at ECEP. Instead of beginning with general principles and eventually getting to applications, engineering educator begins with specifics - a set of observations or experimental data to interpret, or a complex real-world problem to solve. As the students attempt to analyze the data or scenario or solve the problem, they generate a need for facts, rules, procedures, and guiding principles, at which point they are either presented with the needed information or helped to discover it for themselves [11].

Before teaching a topic or series of lessons using any inductive method, engineering educators should write learning objectives that define what the student should be able to do (explain, calculate, derive, design, model, critique) when the instruction has been concluded. If instructional objectives are at a low cognitive level, requiring almost exclusively rote memorization of facts or mechanical substitution into formulas, there is no reason to use an inductive method. The objectives should guide the choice of focus problems, learning activities, and assessment methods.

McKeachie [13], Bligh [14] and Nilson [15] cite numerous studies indicating that the lecture is as effective as any other method in conveying factual knowledge. But on other criteria: attitude change, development of thinking and problem solving skills, transfer of knowledge to new situations, student satisfaction with the course, motivation for further learning and post-course retention of knowledge - the classical lecture falls short of more student active methods such as discussion. Actually the interactive lecture can be highly motivational, but its success depends on the lecturer in engineering education. Interactive lectures are used for presenting general background information - the main ideas, thus providing systematic basic knowledge, followed by the constructivist approach focusing on particular applications and problems being centred in the study programme for engineering educators.

According to Prince and Felder [11] inductive teaching and learning is an umbrella term that encompasses a range of instructional methods, including problem-based learning, project-based learning and just-in-time teaching. They are all learner centred meaning that they impose more responsibility on students for their own learning than the traditional lecture-based deductive approach does. They can all be characterized as constructivist methods, building on the widely accepted principle that students construct their own versions of reality rather than simply absorbing versions presented by their teachers. Students are active and construct knowledge linking new information to previous knowledge.

Quantity of knowledge is not synonymous with quality. We can be rich in knowledge but poor in sense. Understanding is what makes sense of otherwise disparate items of information. Understanding is a worthwhile goal, it can reduce a chaotic mental world to a more predictable and satisfying state. It also facilitates further learning and recall of knowledge, particularly in novel situations. Understanding is often acknowledged to be an aim of learning. A teacher is not the only one who can regulate learning. Learners themselves can monitor and control their learning by developing meta-cognitive skills.

Neither adequate strategies nor appropriate conceptions will count for anything unless students are willing to learn. Students should see the particular value of understanding, expect to have a worthwhile degree of success and feel the emotional price will not be too high to pay.

In 2011-2012 a research on effectiveness of the strategies used in teaching engineering has been carried out at ECEP. A special questionnaire consisting of 30 questions was elaborated for students of the master curriculum for technical teachers. 36 students participated in the research, $58 \%$ of them were male students. The aim of the research was to evaluate the quality of the curriculum and the quality of teaching in order to improve technical teacher education at TUT.

Students were asked to choose answers within the scale of 6 level graduations ( 0 - absolutely do not agree ..... 5 fully agree).

The subjects of the curriculum and syllabi were highly evaluated by students, the average valuation being 4.25 of maximum 5 (the lowest grade 3.89 was given to the subject Information Technology and the highest one 4.62 to Engineering Pedagogy Science). Evaluation of syllabi and subjects included questions like whether the subject offered interesting subject matter, up to date information, and available high quality learning materials, connection of theory and practice, provided contemporary learning environment, clear and obtained learning objectives, strength of purpose of subjects and curriculum, considering previous knowledge of learners).

Teaching quality, clearness, used teaching strategies and models were also evaluated. Students claimed that professors had excellent knowledge in subject they teach (average 4.98 of maximum 5), professors presented 
contemporary subject matter (4.71), professors' preparation for lessons was of high quality (4.83). Students affirmed that clearness of presentation and the level of understanding of information presented by professors were appropriate (4.91), lessons were enthralling (4.63) and with adequate speed (4.75), professors followed the syllabi (4.86) and achieved the goals (4.89). Students confirmed in their answers that professors took account of students' different learning styles (4.78) and preliminary knowledge (4.87), used different effective and contemporary teaching methods, models and strategies (4.91), informed students afore of requirements of exams and tests (4.90), questions asked and answered by professors were clear, understandable and made students analyse the presented subject matter (4.81), professors enthused students' individual work and group work (4.82). Students agreed that professors possessed skills in presentation and usage of teaching technology (4.78), and gained good contact with the audience (4.81), professors were wellintentioned and tactful (4.92), and punctual in time (4.95).

The highest possible valuation was given to professors of Engineering Pedagogy Science and to supervisors of Teaching Training Practice at school.

$98 \%$ of students were content with chosen speciality and relevant curriculum. $90 \%$ of students were eager to study additional engineering speciality subjects in order to update afore acquired knowledge. $100 \%$ of students affirmed that they were aware of the curriculum objectives afore starting their studies, subjects in the curriculum were in logical order of succession, with clear interdisciplinary connections, and there were sufficient amount of electives in the curriculum.

$92 \%$ of alumni confirmed that they have implemented new interactive teaching strategies, models and methods acquired during their passed technical teacher education at ECEP.

Feedback from students has been positive and supportive and confirmed that strategies used in teaching at ECEP capacitate teaching for understanding.

Through inductive teaching students at ECEP are taught the procedures and processes of thinking and to recognise, define and solve open-ended problems which can be learned by practicing. Thus students assume more responsibility and are better motivated, becoming successful lifelong learners and better practitioners in their future teaching profession. Inductive teaching encourages students to analyse, critique, judge, compare, contrast, evaluate, assess, create, predict, apply, use, implement and gain professional perfection.

\section{CONCLUSIONS}

Students have different levels of motivation, different attitudes about teaching and learning, and different responses to specific classroom environments and instructional practices. The more thoroughly instructors understand the differences, the better chance they have of meeting the diverse learning needs of all of their students.

Schools have typically neglected teaching for thinking, and transfer thinking operations from one subject to another and to real life. Emphasis has been on information acquisition and low-level content. Students need to do more than learn information. Thinking skills and proc- esses need to be learned, as does the ability to use these in a variety of contexts. If teaching and learning are to be authentic, teachers need to teach for thinking. Some educators see stand-alone thinking skills or process learning as ineffective, believing that thinking skills are discipline specific and little transfer, if any will occur. Others say a context is always required, but thinking skills are generic and teaching for transfer can occur. What should schooling accomplish? Authentic, active, collaborative, problem-based learning is the direction proposed, along with learning to think.

Understanding is worthwhile, it is a requirement of many programmes of study and its achievement needs skill, support, effort and time. Supporting understanding is not an add-on piece of learning environment. Leaning environment is complex and highly integrated its parts cannot be taken out, tinkered with and replaced without the need to consider the parts being meshed with. Teaching for understanding calls for the mental engagement of teachers and students. Successful teaching for understanding brings rewards for both.

\section{REFERENCES}

[1] N. Entwistle, Motivational Factors in Students' Approaches to Learning, in Schmeck, R.R., (Ed.), Learning Strategies and Learning Styles, Ch. 2, New York, N.Y.: Plenum Press, 1988.

[2] D. W. Tileston, What Every Teacher Should Know about Effective Teaching Strategies, Hawker Brownlow Education, 2007.

[3] P. D. Eggen, D. P. Kauchak, Strategies and Models for Teachers Teaching Content and Thinking Skills, $5^{\text {th }}$ edition, Pearson Education Inc, 2006.

[4] P. R. Burden, D. M. Byrd, Methods for Effective Teaching Meeting the Needs of All Students, $5^{\text {th }}$ edition, Pearson education Inc, 2011.

[5] H. R. Lang, D. N. Evans, Models, Strategies and Methods for Effective Teaching, Pearson Education Inc, 2006.

[6] L. Raths, J. Wassermann, S. Wassermann, Pupil activity reference book: Thinking Skills development program. Westecher, IL:Benefic Press, 1978.

[7] C. Hughes, B. Jones, Integrating thinking skills and processes into content instruction. Presented to the $3^{\text {rd }}$ Annual Conference, Association for Supervision and Curriculum Development, Boston, 1988.

[8] R. J. Marzano, D. J. Pickering, J. E. Pollock, Classroom Instruction that works: Research-based Strategies for Increasing Student Achievement. Upper saddle River, NJ:Merrill/Prentice-Hall, 2005.

[9] A. Melezinek, “Ingenieurpädagogik - Praxis der Vermittlung technischen Wissens”, Springer Verlag, Wien/New York, 4th edition, 1999. http://dx.doi.org/10.1007/978-3-7091-6802-8

[10] H. Kipper, T. Rüütmann, Strategies and Techniques of Questioning Effectuating Thinking and Deep Understanding in Teaching Engineering at Estonian Centre for Engineering Pedagogy. Problems of Education in the 21st Century, 19, 36 - 45, 2010.

[11] M. J. Prince., R. M. Felder, Inductive Teaching and Learning Methods: Definitions, Comparisons, and Research Bases, Journal of Engineering Education, 95(2), 123-138, 2006. http://dx.doi.org/10.1002/j.2168-9830.2006.tb00884.x

[12] S. Paik, Ten Strategies that Improve Learning. Educational Horizons, 81(2), 83-85, 2003.

[13] W. J. McKeachie, M. Svinicki, McKeachie's Teaching Tips Strategies, Research, and Theory for College and University Teachers, Houghton Miffllin Company, 2006.

[14] D. A. Bligh, What's the Use of Lectures? San Francisco, Jossey Bass, 2000.

[15] L. B. Nilson, Teaching at Its Best, A Research-Based Resource for College Instructors, Anker Publishing Company, 2003. 


\section{AUTHORS}

Hants Kipper is a Lecturer at Estonian Centre for Engineering Pedagogy at Tallinn University of Technology, Ehitajate tee 5, 19086, Tallinn, Estonia (e-mail: hants.kipper@ttu.ee ), Member of IGIP IMC.

Tiia Rüütmann is Associate Professor, Head of Estonian Centre for Engineering Pedagogy at Tallinn University of Technology, Ehitajate tee 5, 19086, Tallinn, Estonia (e-mail: tiia.ruutmann@ttu.ee). Member of IGIP EC.

This article is an extended and modified version of a paper presented at the IGIP2012 conference, held 26 - 28 September 2012, in Villach, Austria. Received 30 November 2012. Published as resubmitted by the authors 28 January 2013. 